\title{
Transportation noise and annoyance related to road traffic in the French RECORD study
}

\author{
Julie Méline ${ }^{1,2^{*}}$, Andraea Van Hulst ${ }^{3,4}$, Frédérique Thomas ${ }^{5}$, Noëlla Karusisi ${ }^{1,2}$ and Basile Chaix ${ }^{1,2}$
}

\begin{abstract}
Road traffic and related noise is a major source of annoyance and impairment to health in urban areas. Many areas exposed to road traffic noise are also exposed to rail and air traffic noise. The resulting annoyance may depend on individual/neighborhood socio-demographic factors. Nevertheless, few studies have taken into account the confounding or modifying factors in the relationship between transportation noise and annoyance due to road traffic. In this study, we address these issues by combining Geographic Information Systems and epidemiologic methods. Street network buffers with a radius of $500 \mathrm{~m}$ were defined around the place of residence of the 7290 participants of the RECORD Cohort in lle-de-France. Estimated outdoor traffic noise levels (road, rail, and air separately) were assessed at each place of residence and in each of these buffers. Higher levels of exposure to noise were documented in low educated neighborhoods. Multilevel logistic regression models documented positive associations between road traffic noise and annoyance due to road traffic, after adjusting for individual/ neighborhood socioeconomic conditions. There was no evidence that the association was of different magnitude when noise was measured at the place of residence or in the residential neighborhood. However, the strength of the association between neighborhood noise exposure and annoyance increased when considering a higher percentile in the distribution of noise in each neighborhood. Road traffic noise estimated at the place of residence and road traffic noise in the residential neighborhood (75th percentile) were independently associated with annoyance, when adjusted for each other. Interactions of effects indicated that the relationship between road traffic noise exposure in the residential neighborhood and annoyance was stronger in affluent and high educated neighborhoods. Overall, our findings suggest that it is useful to take into account (i) the exposure to transportation noise in the residential neighborhood rather than only at the residence, (ii) different percentiles of noise exposure in the residential neighborhood, and (iii) the socioeconomic characteristics of the residential neighborhood to explain variations in annoyance due to road traffic in the neighborhood.
\end{abstract}

Keywords: Transportation noise, Annoyance, Residential neighborhood

\section{Introduction}

Road transportation is the first means of transport in urban areas and is one of the main sources of impairment of residential quality and discourages recreation in residential environments. Among all nuisances, noise is the first source of annoyance mentioned by the Ile-de-France residents [1]. This major annoyance related to transportation noise could lead to deleterious effects on health such as sleeping disorders [2,3], stress, and risk of cardiovascular diseases [2,4]. Annoyance due to transportation noise is well documented

\footnotetext{
* Correspondence: julie.meline@inserm.fr

'Inserm, U707, Paris, France

${ }^{2}$ Université Pierre et Marie Curie-Paris6, UMR-S 707, Faculté de Médecine Saint-Antoine, Paris, France

Full list of author information is available at the end of the article
}

[5] by studies and meta-analyses that assessed levels of annoyance for each level of traffic noise [2,3,5-13]. Similarly, according to Bruitparif [14], road, rail, and air traffic are respectively the first, the third, and the second sources of annoyance in the Ile-de-France region (the Paris region).

Many areas exposed to road traffic noise are also exposed to aircraft and railway noise [9]. However, most studies have taken into account the emissions of a unique transportation mode (road, rail, or air traffic) when documenting associations between noise and annoyance $[15,16]$. Moreover, in addition to the source of noise, the degree of annoyance may also depend on socio-demographic factors including gender, age, education and income levels [5,9]. However, only few studies

\section{Biomed Central}


investigating the relationships between transportation noise and annoyance have either adjusted for individual and specifically neighborhood socio-demographic factors or have considered these variables as potential modifiers of the association of interest $[17,18]$.

In this study, we examined the associations between outdoor road, rail, and air traffic noise and annoyance related to road traffic in the Ile-de-France region, after adjusting for individual and neighborhood socioeconomic factors and for a typology of neighborhoods based on multiple urban and environmental factors. We compared the relationships that were documented between transportation noise and annoyance due to road traffic: 1) when different objective sources of transportation noise were considered (i.e., road traffic, rail traffic and air traffic) and 2) when exposure to outdoor transportation noise was assessed at the exact place of residence or in the neighborhood around the residence. Rail traffic noise was taken into account based on the hypothesis that the addition of other noise nuisances to the road traffic noise could strengthen the feeling that there is too much road traffic in the neighborhood (synergistic effect of different sources of noise). Moreover, in addition to an analysis of the spatial distribution of exposure to transportation noise in the Ile-de-France region, we examined whether the associations between transportation noise and annoyance due to road traffic were modified by individual and neighborhood socio-economic factors.

\section{Materials and methods}

\section{Study population}

The Residential Environment and CORonary heart Disease (RECORD) Cohort (www.record-study.org) comprises 7290 residents of the Ile-de-France region who were recruited between March 2007 and February 2008. The participants were recruited during 2-hour medical checkups conducted in four health centers affiliated with the Centre d'Investigations Préventives et Cliniques located in the Ile-de-France region. As eligibility criteria, participants were 30-79 years old, were able to fill survey questionnaires in French, and had to reside in one of 10 (out of 20) administrative divisions of Paris or in 111 other municipalities selected in the Paris metropolitan area. The $a$ priori selection of these municipalities aimed to include suburban and urban areas from contrasted socioeconomic backgrounds. All participants (100\%) were precisely geocoded based on their residential address in 2007-2008. Additional details on the study are reported elsewhere [19]. The study protocol was approved by the French Data Protection Authority.

\section{Annoyance due to road traffic}

In a study of the concept of noise annoyance conducted by a panel of experts of different countries in charge of evaluating noise annoyance [20], noise annoyance was closely associated with the notion of "nuisance" and "disturbance". Annoyance was also linked to the concepts of negative feelings and evaluations [18,20]. Annoyance related to road traffic was defined from the RECORD Study questionnaire based on the following item: "do you find that in your neighborhood there is too much road traffic?". This item put the emphasis on a negative aspect ("too much") and was therefore referring to "road traffic nuisance" or in other terms to annoyance due to road traffic (thus a broader concept than "road traffic noise annoyance" itself since the survey question was related to all aspects of road traffic nuisance indistinctively: noise, air pollution, security, etc.). The degree of annoyance was rated on a 4 level scale: 'Yes, definitely', 'Yes, probably', 'Probably not', and 'Definitely not'. A binary variable of annoyance was defined with value 1 for the 'Yes, definitely' answer, and 0 otherwise.

\section{Individual and neighborhood variables}

Gender was coded as a binary variable. Age was categorized into 3 classes: 30-44; 45-59; 60-79 years old. Education was divided into 4 classes: no education (low); primary and lower secondary education (middle-low); higher secondary and lower tertiary education (middle-high); and upper tertiary education (high). Nonownership of dwelling was coded as a binary variable.

Based on separate sources of data geocoded at the building level, two neighborhood socioeconomic variables were defined in buffers of $500 \mathrm{~m}$ of radius centered on the residence of the participants. These buffers took into account the street and road network around the residence (i.e., the radius of $500 \mathrm{~m}$ was defined along the street network). The educational level of residents in the neighborhood was defined as the proportion of residents aged $>25$ years with an upper tertiary education (2006 Census). The median income in 2006 (General Directorate of Taxation) of households residing in these buffers was also determined. These two variables were then divided into 4 categories with a similar number of participants. We also distinguished the participants residing in the city of Paris (county \#75), the participants living in the "inner suburbs" (first belt of counties around Paris; counties \#92, 93, and 94), and the participants living in the "outer suburbs" (second belt of counties around Paris; counties \#78, 91, 94, and 95).

Finally, we used a typology of neighborhoods elaborated for the RECORD Study in the Ile-de-France region [21]. This typology, established in two steps with a factor analysis and a cluster analysis, provides a grouping of neighborhoods with comparable characteristics but which are not necessarily geographically adjacent. Six neighborhood types were identified from the combination of 13 neighborhood variables (among the numerous variables initially considered), including: 4 indicators of the built environment 
(proportion of the neighborhood area covered with buildings, density of intersections, average street block length, deterioration of the physical environment in the neighborhood); 2 indicators of air pollution (measured concentrations of $\mathrm{PM}_{10}$ and $\mathrm{NO}_{2}$ in the neighborhood); 4 indicators of the service environment (total number of destinations, number of supermarkets, number of grocery stores, incoming and outgoing traffic by public transportation); and 3 indicators of neighborhood social interactions (neighborhood stressful social interactions, neighborhood mistrust and hostility, and stigmatized neighborhood identity). The detailed methodology to derive this neighborhood typology has been reported elsewhere [21]. Two urban central neighborhoods, two urban neighborhoods, and two suburban neighborhoods were identified, with more or less advantaged social interactions in each urbanization stratum

\section{Transportation noise variables}

The (road, rail, air) transportation noise data were provided by Bruitparif. This non-Governmental Organization is in charge of gathering published layers of noise modeled by each municipality or grouping of municipalities in the Paris metropolitan area from 2007 onwards, according to the Environmental Noise Directive [2]. We chose to use these noise maps to characterize transportation noise exposure at the place of residence and residential neighborhood scales and to analyze the relationship with annoyance due to road traffic reported for the residential neighborhood because a high correspondence has been documented between the relationships of observed or predicted noise exposure with noise annoyance at these scales [22]. The measurement of noise in this database is in $\mathrm{dB}(\mathrm{A})$ and is expressed with the standard European Lden and $\mathrm{Ln}$ indicators. In the $\mathrm{dB}(\mathrm{A})$ unit of measurement (Decibel with a A-weighted filter), the filter A scale corresponds to people's natural hearing sensitivity recognition at different sound frequencies [5,9]. Following previous work [23], we chose to use the Lden indicator, defined as the A-weighted equivalent continuous noise level (LAeq) over a $24 \mathrm{~h}$ period but in which levels during the evening and night are increased by $5 \mathrm{~dB}(\mathrm{~A})$ and $10 \mathrm{~dB}(\mathrm{~A})$, respectively.

The modeled layers for each municipality were obtained by Bruitparif from two types of institutions: local authorities and government services. According to the Environmental Noise Directive, the local authorities had to elaborate complete maps of road, rail, and air traffic noise. As the local authorities relied on different engineering offices to estimate noise levels on their territory, there was some heterogeneity in the noise modeling methodology. For instance in Paris, the commissioned engineering office used the EASYMAP model (SIRIATECH, Roubaix, France). This model was based on (1) the environmental noise prediction software MITHRA (Scientific and Technical Centre for Buildings, Grenoble, France), (2) the geographical information system ArcGIS (ESRI, Redlands, California, USA) and (3) the environmental management information system Drag\&Fly (SIRIATECH, Roubaix, France) to generate noise calculations and noise mapping across Paris in two or three dimensions. Additional explanations (input parameters, detailed methodology) on the modeling of noise in Paris are provided in a previous article [23].

The layer provided by the city of Paris was built from a raster with noise information on a $2 \times 2$ meter cell grid, at 1.5 meter from the ground, and taking into account the distribution of buildings. Differently, the layers provided by the other cities in the Ile-de-France region were vector files of noise points or noise lines, modeled every 2 meters at 4 meters from the ground and at 2 meters from the buildings' frontage. Despite this heterogeneity, an overall noise map was built by Bruitparif to comply with the Environmental Noise Directive Recommendations. When municipalities did not generate or release a noise database for their territory, Bruitparif completed the missing information with a noise database elaborated by government services. These institutions had to elaborate maps of road, rail, and air traffic noise that were less precise than those produced by the local authorities. Indeed, only roads with more than 6 million vehicles per year, railways with more than 60000 trains per year, and airports with more than 50000 movements per year were taken into account in this governmental modeling of noise. Bruitparif processed and homogenized all these layers according to the Environmental Noise Directive, in order to create a noise database at the scale of the Ile-de-France region. From the vector layers of noise points or noise lines and the raster layer provided by local authorities and government services with noise levels between 30 and $80 \mathrm{~dB}(\mathrm{~A})$, Bruitparif generated a layer of polygons of noise levels with a subdivision in 5 to $5 \mathrm{~dB}(\mathrm{~A})$ classes $(55-<60 ; 60-<65 ; 65-$ $<70 ; 70-<75$; and 75- $<80$ ). The raw data of the final Bruitparif map were collected between 2007 and 2011.

The geographical processing of the noise database was performed with the ArcInfo 10 Geographic Information System. The Environmental Noise Directive established that noise levels equal to or above $55 \mathrm{~dB}(\mathrm{~A})$ could have an impact on human health. However, in order to take into account the heterogeneous environments in the Ilede-France region, from quiet rural areas to busy urban areas, we also integrated levels of noise from the minimum level of $30 \mathrm{~dB}(\mathrm{~A})$ corresponding to the rural environment at night to the established European level of $55 \mathrm{~dB}(\mathrm{~A})$. The Bruitparif layers of noise polygons (from 55 to $80 \mathrm{~dB}(\mathrm{~A})$ ) were juxtaposed in order to build one 
layer of noise polygons for each transportation type (road, rail, air) at the scale of the Ile-de-France region. To integrate all noise classes from 30 to $80 \mathrm{~dB}(\mathrm{~A})$, we processed and homogenized the original layers of noise points elaborated by local authorities and government services (that include noise classes between 30 and $50 \mathrm{~dB}(\mathrm{~A}))$ following the general process used by Bruitparif, in order to elaborate layers of noise polygons. The final layer of noise polygons for each transportation mode (road, rail, air) at the scale of the Ile-de-France region was generated by filling missing portions of the Bruitparif layer with information from the layer of polygons from the Government/local authorities (ArcGIS update Tool).

In order to estimate noise exposure at the place of residence of the participants, outdoor road, rail, and air traffic noise levels were extracted at each geocoded place of residence. In order to estimate noise exposure of participants in the residential neighborhood, we determined buffers around the places of residence (Figure 1). These buffers were centered on the exact residential building of the participants and had a radius of $500 \mathrm{~m}$. The shape of the buffers took into account the street and road network. A radius of $500 \mathrm{~m}$ was chosen and the street network was taken into consideration in order to characterize as precisely as possible the outdoor noise exposure of participants moving around their residence during the day. Indeed, in most places in the Ile-de-France region, people are likely to find basic services within a $500 \mathrm{~m}$ radius around their residence [24]. Moreover, different studies based on the RECORD Study have shown that contextual variables are particularly strongly associated with health outcomes when measured within $500 \mathrm{~m}$ radius buffers $[25,26]$.

As shown in Figure 2, the ArcGIS intersect tool was used to identify the portion of the different polygons of noise that fell into the buffer of each participant (the operation was performed for each layer of road, rail, and air traffic noise). Then according to the proportion of the surface of each class of noise that fell into the buffer of each participant, the following noise variables were defined with the SAS software: 25th percentile of noise in the buffer of each participant, median noise value, and 75th percentile of the noise value in the buffer of each participant. The median was used rather than the average, because it was found relevant to consider

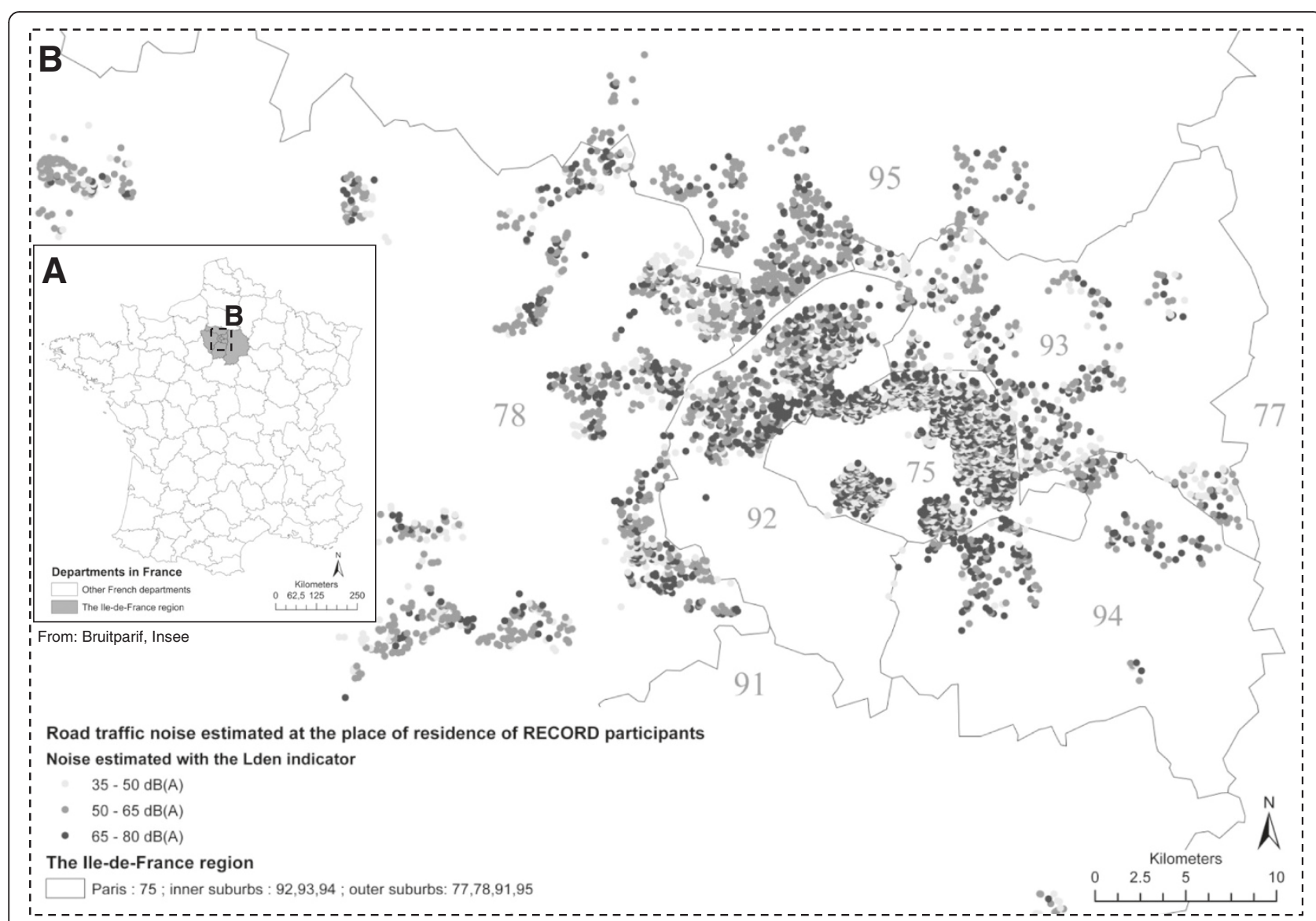

Figure 1 Location of places of residence of RECORD participants in the lle-de-France region in France. $(\mathbf{A}, \mathbf{B})$ and distribution of road traffic noise estimated at the place of residence (B). 


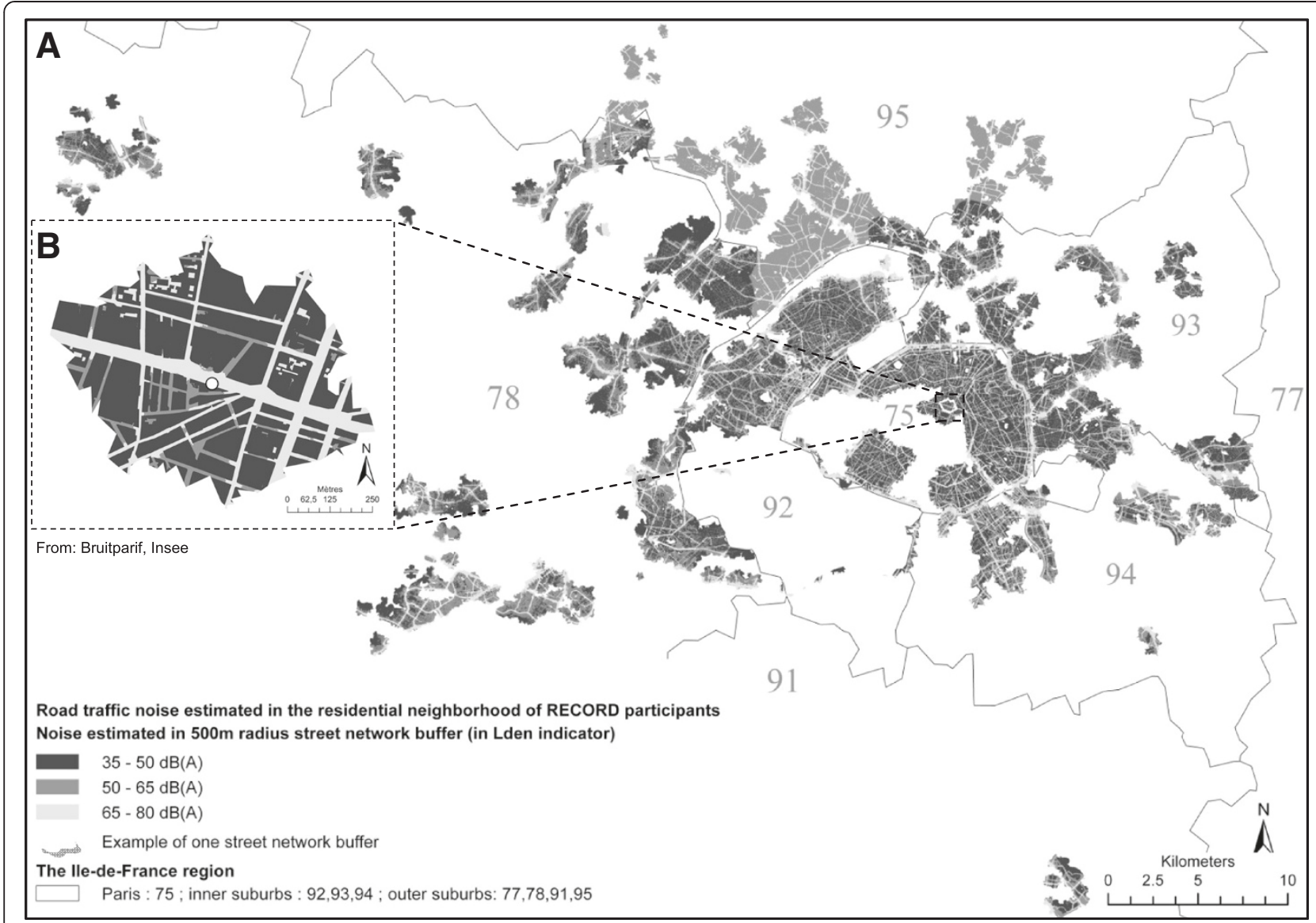

Figure 2 Distribution of road traffic noise estimated in the residential neighborhood for all RECORD participants (A) and for one participant (B) in the Ile-de-France region.

different percentiles in order to take into account the variability of noise exposure into the buffer for people going through it and to identify people exposed to high levels of noise that would not be captured by an indicator of central tendency.

The areas with modeled information on noise did not cover the entire territory of the Ile-de-France region and the areas with modeled information on noise differed in their coverage according to the type of transportation mode. Some counties and some municipalities within certain counties were completely excluded from the modeling and referred to non-modeled administrative territories. These non-modeled administrative territories differed depending on the type of transportation noise (road, rail or air). Within the administrative territories that were part of the modeling, the modeling for a certain source of noise was not performed in parts of the territory that were too far from this source of noise for being affected. Indeed, the accuracy of the distance of noise from the roads or railways from modeling process is defined essentially in taking into account the characteristics of the environmental context (urban or rural) and of the degree of absorption of noise by the environment (ground and building). All these areas were excluded from the analyses because of an absence of modeled data. Therefore, after excluding the missing values and in taking into account the administrative territories that were part of the modeling with modeled noise data (from 30 to $80 \mathrm{~dB}(\mathrm{~A})$ ) defined for each transportation type (road, rail and air), different samples were defined: 6194 and 6539 participants for road traffic noise estimated at the place of residence and in $500 \mathrm{~m}$ radius street network buffers, and 3945 and 4265 participants for rail traffic noise estimated at the place of residence and in the buffers. The number of participants who were exposed to aircraft noise in our sample $(\mathrm{n}=78$ at the place of residence and $n=152$ in the residential neighborhood) was too weak to investigate associations between aircraft noise and annoyance, because of a lack of statistical power.

\section{Statistical analysis}

Descriptive analyses assessed variations of neighborhood factors (education, income) according to administrative 
division (Additional file 1: Table S1) and variations in transportation noise according to the different contextual variables (Table 1 and Additional file 1: Table S2). Multilevel logistic regression analyses were conducted to examine associations between outdoor road and rail traffic noise levels and annoyance related to road traffic. Analyses were based on the different samples excluding observations with missing information for each noise exposure variable: road and rail traffic noise; estimated at the residence or in the residential neighborhood. The multilevel models were estimated with participants nested within census block group neighborhoods. The 1760 census block group neighborhoods represented in the present analysis, defined for the Population Census, are relatively homogeneous in term of sociodemographic and housing characteristics (the median number of residents per neighborhood represented in our study was 2529 in 2006 (interquartile range: 2159 to 3111 ).

First, for each sample, an empty model was estimated. Second, we derived parsimonious models retaining only the individual/contextual sociodemographic variables that were independently associated with annoyance related to road traffic (among the following variables: gender, age, nonownership of dwelling, individual education, household income, neighborhood median income, neighborhood education, and the neighborhood urban typology) (Model 1 in Table 2). Third, in order to compare associations with noise variables estimated at the place of residence and noise variables estimated in $500 \mathrm{~m}$ radius street network buffers, we defined two sets of noise variables: 1) two categorized noise variables (estimated at the place of residence and corresponding to the median noise value in the neighborhood buffer) that were subdivided into classes with cutoff values every $10 \mathrm{~dB}(\mathrm{~A})$ from 30 to $80 \mathrm{~dB}(\mathrm{~A})$ and 2 ) four standardized continuous noise variables, estimated at the place of residence and corresponding to the 25th, 50th, and 75th percentiles of noise values in each neighborhood buffer. The associations of annoyance due to road traffic (adjusted for the individual/neighborhood factors) with the two categorized noise variables correspond to models $2 \mathrm{~A}$ and $2 \mathrm{~B}$ in Table 3, and to the models shown in Additional file 1: Table S3, while the associations with the standardized noise variables correspond to models $4 \mathrm{~A}, 4 \mathrm{~B}$, $4 C$ and $4 \mathrm{D}$ in Table 4 and to the models shown in Additional file 1: Table S4. Fourth, modification of the relationship between road traffic noise and annoyance due to road traffic by rail traffic noise and modification of the relationship between transportation noise and annoyance due to road traffic by individual and neighborhood income and education were tested, both on a multiplicative scale and on an additive scale as previously recommended [27] (Table 5 and Additional file 1: Tables S5 and S6). We did not estimate relationships between outdoor air traffic noise and annoyance due to road traffic because of a lack of statistical power. All regression analyses were conducted with SAS software.

\section{Results and discussion}

\section{Road traffic noise by neighborhood contexts}

Figures 1 and 2 report the spatial distribution of outdoor transportation noise. Table 1 and Additional file 1: Table S2 provide levels of noise according to the neighborhood variables and according to the administrative division at the county level. When considering noise at the place of residence or the 25th and 50th percentiles of noise values in neighborhood buffers, outdoor road traffic noise surprisingly increased from Paris to the outer suburbs. However, when considering the 75 th percentile, outdoor road traffic noise increased from the outer suburbs to Paris (Table 1). Regarding neighborhood education, for most noise variables, noise levels tended to increase from high educated neighborhoods to low educated neighborhoods. This finding is in contrast with a previous study of our group [23] that showed a positive relationship between neighborhood socioeconomic status, including neighborhood education, and exposure to noise. The discrepancy in the findings may be due to the fact that the previous study only considered the city of Paris, while the present work takes into account a broader territory from the Ile-de-France region. These updated findings are of interest for the assessment of situations of environmental injustice and highlight the need to study the variations in the patterns of environmental inequalities across various economic, social and cultural settings [28].

\section{Individual/neighborhood variables associated with annoyance due to road traffic}

As also documented in previous literature [29-31], the annoyance due to road traffic was not associated with age or gender. The odds to report annoyance due to road traffic increased with decreasing household income, and independently with decreasing neighborhood income as well. After adjustment for the other individual/ neighborhood factors, the odds of annoyance were higher in central urban neighborhoods than in urban and suburban neighborhoods, with a much higher prevalence of annoyance in central urban neighborhoods with an intermediate than with a high social standing (Table 2).

\section{Road traffic noise and annoyance due to road traffic}

The analyses showed that outdoor road traffic noise was associated with annoyance due to road traffic, after adjusting for individual and neighborhood socioeconomic variables. In all the models tested (Tables 3 and 4), the risk of being annoyed by road traffic increased with the level of noise. For example, in models 
Table 1 Spatial distribution of road traffic noise, according to the administrative division in counties, neighborhood urban typology, and neighborhood education (RECORD Cohort study)

\begin{tabular}{|c|c|c|c|c|c|c|c|c|}
\hline \multirow[t]{3}{*}{ Variables } & \multicolumn{2}{|c|}{$\begin{array}{l}\text { Road traffic noise at the } \\
\text { place of residence (with } \\
\text { the Lden indicator and in } \\
\qquad \mathrm{dB}(\mathrm{A}) \text { ) }\end{array}$} & \multicolumn{2}{|c|}{$\begin{array}{l}\text { Road traffic noise at the } 25 \text { th } \\
\text { percentile of } 500 \mathrm{~m} \text { radius street } \\
\text { network buffers around the place } \\
\text { of residence (with the Lden } \\
\text { indicator and in } \mathrm{dB}(\mathrm{A}) \text { ) }\end{array}$} & \multicolumn{2}{|c|}{$\begin{array}{l}\text { Road traffic noise at the median } \\
\text { of } 500 \mathrm{~m} \text { radius street network } \\
\text { buffers around the place of } \\
\text { residence (with the Lden } \\
\text { indicator and in } \mathrm{dB}(\mathrm{A}) \text { ) }\end{array}$} & \multicolumn{2}{|c|}{$\begin{array}{l}\text { Road traffic noise at the } 75 \text { th } \\
\text { percentile of } 500 \mathrm{~m} \text { radius street } \\
\text { network buffers around the } \\
\text { place of residence (with the } \\
\text { Lden indicator) in } \mathrm{dB}(\mathrm{A})\end{array}$} \\
\hline & \multicolumn{2}{|c|}{$N=6194$} & \multicolumn{2}{|c|}{$N=6539$} & \multicolumn{2}{|c|}{$N=6539$} & \multicolumn{2}{|c|}{$N=6539$} \\
\hline & Mean & $\pm S D$ & Mean & $\pm S D$ & Mean & $\pm S D$ & Mean & $\pm S D$ \\
\hline Total & 56.31 & \pm 11.20 & 43.97 & \pm 7.71 & 49.58 & \pm 9.59 & 61.04 & \pm 6.47 \\
\hline \multicolumn{9}{|l|}{ Ile-de-France region } \\
\hline Outer suburbs & 55.70 & 10.55 & 44.69 & 10.27 & 51.76 & 9.65 & 58.41 & 7.70 \\
\hline Inner suburbs & 58.18 & 9.19 & 46.89 & 6.85 & 53.49 & 8.29 & 61.75 & 6.19 \\
\hline Paris & 55.22 & 13.13 & 40.13 & 1.37 & 43.19 & 7.32 & 62.93 & 4.10 \\
\hline P For Trend* & & $3.42 * 0.0003$ & & $-18.98^{*}<.0001$ & & $-31.05^{*}<.0001$ & & $22.59^{*}<.0001$ \\
\hline \multicolumn{9}{|c|}{ Neighborhood proportion of highly educated residents } \\
\hline Low & 57.45 & \pm 9.13 & 47.33 & \pm 8.07 & 53.86 & \pm 7.35 & 60.36 & \pm 5.45 \\
\hline Mid-low & 56.28 & \pm 11.11 & 44.31 & \pm 8.51 & 50.64 & \pm 9.86 & 60.62 & \pm 7.47 \\
\hline Mid-high & 56.04 & \pm 11.81 & 42.63 & \pm 6.91 & 47.43 & \pm 9.71 & 61.32 & \pm 6.31 \\
\hline High & 55.29 & \pm 12.66 & 41.22 & \pm 5.36 & 45.83 & \pm 9.28 & 61.94 & \pm 6.42 \\
\hline P For Trend* & & $-1.42^{*} 0.078$ & & $-23.56^{*}<.0001$ & & $-26.76^{*}<.0001$ & & $11.27^{*}<.0001$ \\
\hline \multicolumn{9}{|l|}{ Neighborhood typology } \\
\hline Type 1: suburban & 55.01 & \pm 9.28 & 47.10 & \pm 9.82 & 54.86 & \pm 6.50 & 60.33 & \pm 4.97 \\
\hline Type 2: suburban & 55.92 & \pm 10.77 & 43.62 & \pm 9.40 & 50.73 & \pm 9.59 & 57.54 & \pm 8.46 \\
\hline Type 3: urban & 58.12 & \pm 9.38 & 47.32 & \pm 7.33 & 53.86 & \pm 7.73 & 61.22 & \pm 5.50 \\
\hline Type 4: urban & 57.57 & \pm 10.41 & 45.46 & \pm 7.64 & 53.24 & \pm 9.72 & 62.71 & \pm 6.45 \\
\hline Type 5: central urban & 55.71 & \pm 12.80 & 40.00 & \pm 0.00 & 41.54 & \pm 4.79 & 62.26 & \pm 3.24 \\
\hline Type 6: central urban & 54.63 & \pm 13.21 & 40.79 & \pm 3.70 & 42.39 & \pm 6.46 & 62.73 & \pm 4.28 \\
\hline P For Trend** & & $81.63^{* *}<.0001$ & & $1831.84^{* *}<.0001$ & & $963.46^{* *}<.0001$ & & $562.47^{* *}<.0001$ \\
\hline
\end{tabular}


Table 2 Associations estimated from multilevel logistic regression between individual/neighborhood sociodemographic factors and annoyance due to road traffic (Model 1) (RECORD cohort study; N = 6539)

\begin{tabular}{|c|c|c|}
\hline \multirow[t]{3}{*}{ Individual/neighborhood Variables } & \multirow{2}{*}{\multicolumn{2}{|c|}{$\frac{\text { Model 1: Annoyance due to road traffic }}{\mathrm{N}=6539}$}} \\
\hline & & \\
\hline & OR & $95 \% \mathrm{Cl}$ \\
\hline Male (vs Female) & 0.96 & $(0.85 ; 1.10)$ \\
\hline Age & 1.00 & $(0.99 ; 1.00)$ \\
\hline Nonownership of dwelling (vs Owner) & 1.29 & $(1.12 ; 1.48)$ \\
\hline \multicolumn{3}{|l|}{ Individual education (vs High) } \\
\hline Middle-High & 1.11 & $(0.94 ; 1.30)$ \\
\hline Mid-low & 1.31 & $(1.10 ; 1.56)$ \\
\hline Low & 1.28 & $(1.01 ; 1.64)$ \\
\hline \multicolumn{3}{|l|}{ Household income (vs High) } \\
\hline Middle-High & 0.99 & $(0.82 ; 1.21)$ \\
\hline Mid-low & 1.33 & $(1.11 ; 1.61)$ \\
\hline Low & 1.63 & $(1.33 ; 1.99)$ \\
\hline \multicolumn{3}{|c|}{ Neighborhood median income in 500 m street network buffers around the place of residence (vs High) } \\
\hline Middle-high & 1.14 & $(0.91 ; 1.42)$ \\
\hline Mid-low & 1.33 & $(1.06 ; 1.67)$ \\
\hline Low & 1.44 & $(1.12 ; 1.86)$ \\
\hline \multicolumn{3}{|l|}{ Neighborhood type (vs Type 2: suburban, high social standing) } \\
\hline Type 1: suburban, low social standing & 1.26 & $(0.91 ; 1.76)$ \\
\hline Type 3: urban, low social standing & 1.84 & $(1.41 ; 2.39)$ \\
\hline Type 4: urban, high social standing & 1.67 & $(1.32 ; 2.12)$ \\
\hline Type 5: central urban, high social standing & 1.72 & $(1.30 ; 2.28)$ \\
\hline Type 6: central urban, intermediate social standing & 3.68 & $(2.90 ; 4.67)$ \\
\hline Between-neighborhood variance & & $0.79(0.76 ; 0.82)$ \\
\hline
\end{tabular}

$2 \mathrm{~A}$ and $2 \mathrm{~B}$ (Table 3 ), the risk of being annoyed by road traffic was around 3 times higher $(\mathrm{OR}=2.26$; 95\% CI: $1.58,3.21$ and $\mathrm{OR}=3.07$; 95\% CI: 1.80, 5.25, respectively) for the participants in the highest class $(70-<80 \mathrm{~dB}(\mathrm{~A}))$ than for those in lowest class (30 $<40 \mathrm{~dB}(\mathrm{~A}))$ of road traffic noise. Other studies than ours have also assessed associations of annoyance with road traffic noise [32].

Comparing models $2 \mathrm{~A}$ and $2 \mathrm{~B}$ and comparing models 4A, 4B, 4C and 4D (Tables 3 and 4) suggest that it was not possible, due to the wide $95 \%$ confidence intervals (despite differences in OR), to conclude that stronger associations were observed when noise was assessed in the residential neighborhood than at the place of residence. A striking finding from the models assessing noise in the residential neighborhood was that a stronger relationship was documented with the 50th percentile of the noise level in the buffer than with the 25th percentile, and that the relationship was still stronger with the 75 th percentile. A likely explanation is that the louder levels of noise captured by higher percentiles in the neighborhood have a particular impact on annoyance due to road traffic. However, it is important to note that road traffic noise measured at the place of residence and road traffic noise in the residential neighborhood (75th percentile) were independently associated with annoyance, when adjusted for each other.

As shown in Table 5, we documented interactions on the multiplicative scale between the effects on annoyance of road traffic noise estimated in the residential neighborhood or at the place of residence and of neighborhood income or neighborhood education [27]. These interactions indicated that the effect of road traffic noise in the residential neighborhood on annoyance due to road traffic was stronger in affluent and high educated neighborhoods than in deprived and low educated neighborhoods. This finding is coherent with our previous work demonstrating that the affluent part of Paris comprises particularly noisy roads [23]. These affluent 
Table 3 Associations estimated from multilevel logistic regression between road traffic noise estimated at the place of residence $(2 \mathrm{~A})$ and at the median noise value of $500 \mathrm{~m}$ radius street network buffers around the place of residence (2B) and annoyance due to road traffic, adjusted for individual/neighborhood socio-demographic factors (RECORD Cohort Study)

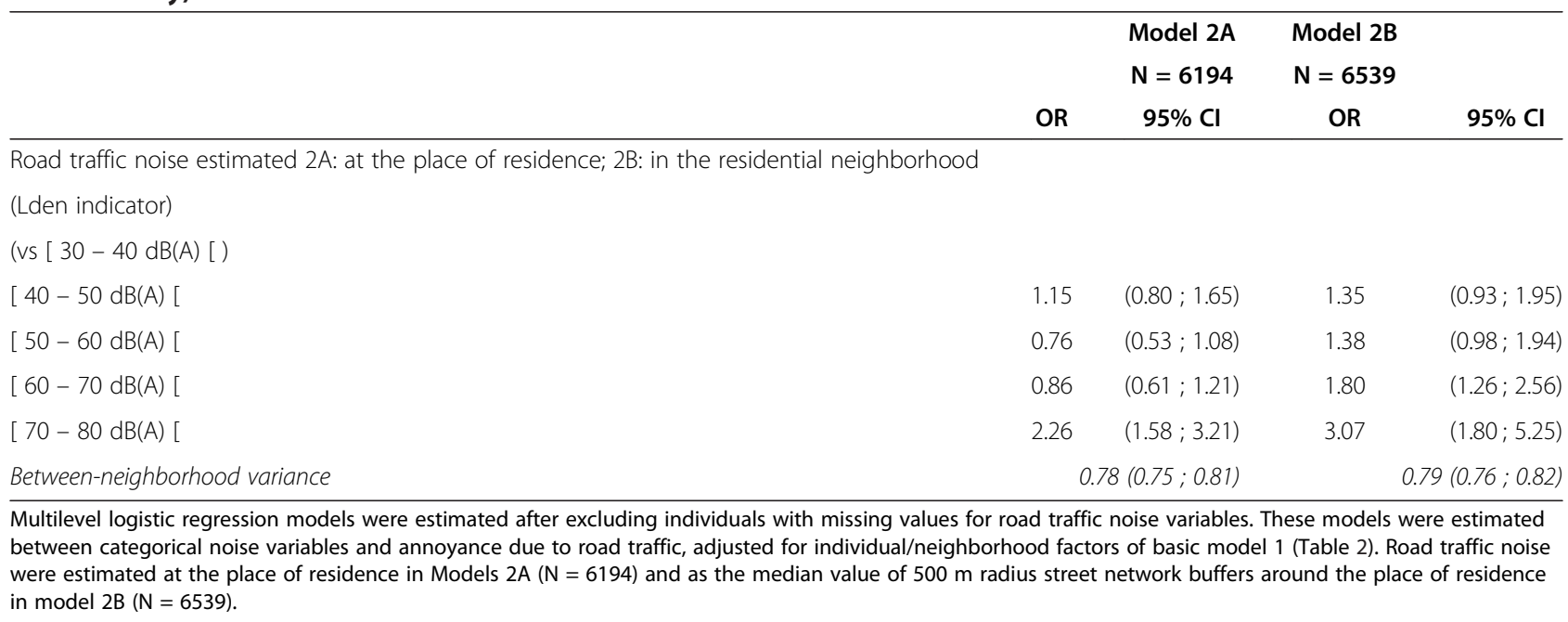

and high educated neighborhoods were located in the central part of the Ile-de-France region, in Paris (Additional file 1: Table S1) which were also the noisiest neighborhoods when the 75th percentile of noise values in the buffer was taken into account (Table 1). The interaction was documented when noise levels in the residential neighborhood were assessed with the 75 th percentile of noise values in the buffer, but not when they were assessed with the 25 th or 50 th percentiles. No interaction was documented between the effects of road traffic noise estimated at the place of residence and these neighborhood variables (Table 5). Also, no interaction was documented between the effect of any of the noise variables and individual socioeconomic variables (results not shown in a Table). Absolutely no interaction was documented on the additive scale (Additional file 1: Table S6).

Rail traffic noise and annoyance due to road traffic

As opposed to outdoor road traffic noise, no associations were documented between outdoor rail traffic noise estimated in the residential neighborhood and annoyance related to road traffic (Additional file 1: Tables S3 and S4). Such an absence of relationship may be attributable, first to the fact that the survey question on annoyance was explicitly related to road traffic, and second to the fact that railway noise (because of the low density of the rail network) may be a weaker source of annoyance than road and

Table 4 Associations estimated from multilevel logistic regression between road traffic noise estimated at the place of residence (4A) and at the 25th (4B), 50th (4C), and 75th percentiles (4D) of noise values of $500 \mathrm{~m}$ radius street network buffers around the place of residence and annoyance due to road traffic, adjusted for individual/ neighborhood socio-demographic factors (RECORD Cohort Study)

\begin{tabular}{|c|c|c|c|}
\hline $\begin{array}{l}\text { Road traffic noise at } \\
\text { the place of } \\
\text { residence }\end{array}$ & $\begin{array}{c}\text { Road traffic noise in the residential } \\
\text { neighborhood ( } 25 \text { th percentile of } \\
\text { noise values of buffers) }\end{array}$ & $\begin{array}{l}\text { Road traffic noise in the residential } \\
\text { neighborhood (median of noise } \\
\text { values of buffers) }\end{array}$ & $\begin{array}{c}\text { Road traffic noise in residential the } \\
\text { neighborhood ( } 75 \text { th percentile of } \\
\text { noise values of buffers) }\end{array}$ \\
\hline OR $(95 \% \mathrm{Cl})$ & OR $(95 \% \mathrm{Cl})$ & OR $(95 \% \mathrm{CI})$ & OR $(95 \% \mathrm{Cl})$ \\
\hline Model 4A $(N=6194)$ & Model 4B $(\mathrm{N}=6539)$ & Model 4C $(\mathrm{N}=6539)$ & Model 4D $(\mathrm{N}=6539)$ \\
\hline $1.20(1.12 ; 1.28)$ & $1.07(0.99 ; 1.15)$ & $1.21(1.11 ; 1.31)$ & $1.29(1.19 ; 1.40)$ \\
\hline $\begin{array}{c}B-N \text { variance: } 0.79 \\
(0.76,0.82) \text { Akaike: } \\
29782.3\end{array}$ & $\begin{aligned} B-N \text { variance: } & 0.79(0.76 ; 0.82) \text { Akaike: } \\
& 31336.4\end{aligned}$ & $\begin{aligned} B-N \text { variance: } 0.79(0.76 ; 0.82) \text { Akaike: } & 31379.9\end{aligned}$ & $\begin{aligned} B-N \text { variance: } & 0.80(0.77 ; 0.83) \text { Akaike: } \\
& 31440.9\end{aligned}$ \\
\hline
\end{tabular}

Multilevel logistic regression models were estimated after excluding individuals with missing values for road traffic noise variables. These models were estimated between standardized continuous noise variables and annoyance due to road traffic, adjusted for individual/neighborhood factors of basic model 1 (Table 2 ). Road traffic noise was estimated in $500 \mathrm{~m}$ radius street network buffers around the place of residence. Abbreviation: B-N: between-neighborhood. 
Table 5 Modification of the association between road traffic noise and annoyance due to road traffic, by neighborhood income and education, on the multiplicative scale (RECORD Cohort Study)

Neighborhood proportion of highly educated residents

$\beta-95 \% \mathrm{Cl}$

$$
\begin{gathered}
-0.09(-0.16 ;-0.02) \\
0.24(0.07 ; 0.41) \\
-0.02(-0.08 ; 0.03)
\end{gathered}
$$

Neighborhood SES* road traffic noise

$B-N$ variance

In the residential neighborhood $(\mathrm{N}=6539)$

Neighborhood SES

Road traffic noise

Neighborhood SES* road traffic noise

$B-N$ variance
Neighborhood median income $\beta-95 \% \mathrm{Cl}$

Multilevel logistic regression models were estimated after excluding individuals with missing values for the two explanatory variables. Noise variable were continuous and standardized (Lden indicator). These variables were estimated at the place of residence or in the residential neighborhood that corresponded to the 75th percentile of noise values in each $500 \mathrm{~m}$ radius street network buffer around the place of residence. Neighborhood income and education were coded as 4-category (low, mid-low, mid-high, and high) ordinal variables. Abbreviation: SES: socioeconomic status; B-N: between neighborhood.

aircraft noise [9]. Calculating the total length of railways and roads from data of the Institute of Urban Planning of the Ile-de-France region and of the National Geographic Institute, we found that the total length of the rail network represents only $2.1 \%$ of the total length of the railway and road network (cumulated) in the Ile-de -France region.

Contrary to rail traffic noise in the residential neighborhood, outdoor rail traffic noise estimated at the place of residence was associated with annoyance due to road traffic, with higher odds of annoyance in the highest class of noise $(70-<80 \mathrm{~dB}(\mathrm{~A}))$ (Additional file 1: Table S3). After adjusting for road traffic noise at the place of residence, the association between rail traffic noise at the place of residence and annoyance due to road traffic also persisted. However, when modification of the relationship between road traffic noise at the place of residence and annoyance due to road traffic by rail traffic noise at the place of residence was tested, no interaction was documented (Additional file 1: Table S5). This absence of interaction suggests that we did not find support for our hypothesis that an alternative source of noise (rail traffic) may exacerbate the effects of road traffic noise on annoyance due to road traffic. No interactions between rail traffic noise and individual/neighborhood socioeconomic variables were also documented (results not shown in a Table).

\section{Between-neighborhood variance in annoyance due to road traffic}

The variance between neighborhoods in the degree of annoyance was substantial in the empty models: equal to 0.75; 95\% CI: $0.72,0.78$ in the samples for road traffic noise, and equal to $0.72 ; 95 \% \mathrm{CI}: 0.69,0.76$ and 0.71 ;
95\% CI: $0.67,0.74$ in the two samples for the analysis of rail traffic noise. As shown in Tables 3 and 4, and in Additional file 1: Tables S3 and S4, there was no evidence that the between-neighborhood decreased when individual/neighborhood variables and noise exposure were taken into account into the models. The fact that the between-neighborhood variance increased in some of the models when adding the covariates is due to the fact that coefficients in successive logistic models are not comparable to each other [33].

\section{Strengths and limitations}

Strengths of this study include the large sample of participants with information available on a large spatial scale (the Ile-de-France region), the collection of data on the perception of road traffic for several thousands of participants, the fact that traffic noise from two important transportation modes was taken into account, the different types of measures of noise that were compared (at the place of residence and within neighborhood buffers, etc.) and the fact that the models were adjusted for multiple individual/neighborhood confounders.

A limitation of this study is the heterogeneity in the source and in the quality of the original transportation noise data provided by municipalities, intermunicipalities, and government services [34]. Another limitation includes the absence of $a$ priori sampling in the recruitment of the participants, with differences in the probability of participation according to neighborhood profiles [35]. However, it is not clear whether and how annoyance due to road traffic might influence participation in the study. Finally, annoyance due to road traffic in the neighborhood was assessed with a single survey item from the RECORD questionnaire. This 
survey question did not allow us to distinguish between the different sources of road traffic nuisances (noise, smell, risk of injury), and could not be used to isolate annoyance related to road traffic noise. However, a study dealing with road traffic nuisances in the United Kingdom showed that with smokes and odors, road traffic noise was the main source of annoyance at the place of residence and when walking in the residential neighborhood [36]. Noise was also the first source of nuisance in the Ile-de-France region in the Health Barometer Study [1]. Besides, around $13 \%$ of people ( $49 \%$ of $26.3 \%$ $(\mathrm{n}=1878)$ of people annoyed by noise at home) declared to be annoyed by road traffic noise at home in the Ile-de -France region in this study [1]. In the Health Barometer, the percentage of people annoyed by noise at home varied in a substantial way according to the location in the metropolitan area: $45.4 \%$ of people living in Paris are annoyed by noise at home vs. $29 \%$ of the residents of inner suburbs, and $25.6 \%$ of those who live in outer suburbs. The prevalence of people annoyed by road traffic noise found in the Health Barometer is relatively coherent with the prevalence of people annoyed by road traffic nuisances in our study, ie.,17.4\% ( $\mathrm{n}=7290)$.Similarly, this percentage in our study showed variations between Paris (23.0\%), the inner suburb (15.7\%), and the outer suburb (15.5\%).

\section{Conclusion and perspectives}

Based on our large sample from a broad territory in the Ile-de-France region, disparities in exposure to road traffic noise were identified according to the educational level of the residents, with higher levels of exposure in low education neighborhoods. Such disparities were documented when noise was assessed at the place of residence and in the residential neighborhood. However, an inversion in the educational gradient of exposure was observed at the highest percentiles of noise exposure in neighborhood buffers (75th percentile), even if the differences between the educational groups were very small. Such patterns may be attributable to the fact that residents of low educated neighborhoods are exposed to a higher level of noise in most part of their neighborhood due to high-traffic and noisy highways, with the resulting noise reaching to a certain extent the places of residence and residential neighborhoods because of a weaker density of the urban network in outer suburbs. On the opposite, there may be a number of high educated neighborhoods with an intermediate level of noise exposure but that comprise very high traffic and noisy roads which the highest noise levels were more often included in residential neighborhoods due to a very dense urban network in the central part of the Ile-de-France region.
Associations were documented between road traffic noise and annoyance due to road traffic, after adjustment for individual/neighborhood factors. The association between rail traffic noise and annoyance due to road traffic was weaker. There was no strong evidence that the association was of different magnitude when noise was measured at the place of residence or in the residential neighborhood. However, the strength of the association between noise in the neighborhood and annoyance tended to increase when considering a higher percentile in the distribution of noise in each neighborhood. Additional analyses not reported here suggest that, once the 75th percentile of road traffic noise in the neighborhood was included into the model, there were no additional relationships with the 25th and 50th percentiles. What matters in the neighborhood as a determinant of annoyance is therefore the highest levels of noise exposure in the environment (as captured by the 75th percentile of noise level in the buffer), rather than the lower levels of noise in the remaining of the neighborhood (as captured by percentiles below the 75th). However, it is important to note that road traffic noise measured at the place of residence and road traffic noise in the residential neighborhood (75th percentile) were independently associated with annoyance, when adjusted for each other.

Interactions of effects indicated that the relationship between road traffic noise exposure in the residential neighborhood (75th percentile) and annoyance due to road traffic was stronger in the most affluent and high educated neighborhoods (i.e., those from Paris). This finding is surprising because authors usually hypothesize that low socioeconomic people are more sensitive to the effects of outdoor noise, e.g., because their dwellings are less correctly isolated [1,37]. However, first, it should be noted that other studies have hypothesized a higher sensitivity to noise among affluent people [17] based on the observation of a higher number of complaints in this population, which may be attributable to the fact that socially advantaged people have a higher awareness of and pay more attention to noise as an environmental exposure, in part because they feel they are able to avoid this exposure (e.g., by moving) contrary to low socioeconomic status people who might feel powerless to decrease their exposure level. Second, such an interaction may also be driven by the fact that a number of affluent and high educated neighborhoods are exposed to very high traffic roads in at least part of the neighborhood. For example, the assumption of a higher impact on annoyance of an increment in noise exposure at higher levels of the noise scale (e.g., higher impact of an increase from 65 to 75 than of an increase from 55 to $65 \mathrm{~dB}(\mathrm{~A}))$ would explain the observed interaction. Third, there may be more behavioral explanations to this 
interaction. People living in the most affluent neighborhoods in urban centers with a large number of services are particularly engaged in walking in their neighborhood. Analyses of walking in the RECORD Study show that a high density of services and a high neighborhood educational level are independently associated with walking. Thus people residing in such neighborhood may be more exposed to road traffic noise in their neighborhood and particularly aware of it, which may also contribute to the reported interaction. Interestingly, the strongest associations between road traffic noise in the residential neighborhood and annoyance documented in affluent and high educated neighborhoods show that it is relevant to study the exposure to noise in the daily environments of people, such as their residential neighborhood.

Overall, our findings suggest that it is useful to take into account (i) the exposure to transportation noise during daily trips in the residential neighborhood rather than only the outdoor exposure level at the residence, (ii) different percentiles of noise exposure in the residential neighborhood, and (iii) the socioeconomic characteristics of the residential neighborhood to explain variations in annoyance due to road traffic in the neighborhood.

To better understand our findings and why there is a spatial discrepancy in the patterns of associations when noise exposure is assessed at the place of residence or in the residential neighborhood, new technologies of mobility and health assessment will be used in our future work. This project, funded by the French Agency for Food, Environmental and Occupational Health \& Safety (ANSES) and by the French Environment and Energy Management Agency (ADEME), will combine Global Positioning System (GPS) tracking, assessment of individual noise exposure with noise sensors, and assessment of annoyance and health with ambulatory monitoring of health indicators. Such an approach will allow us to better characterize the complex interactions between the daily life environments, the multi-exposure to noise, and annoyance and health.

\section{Additional file}

Additional file 1: Table S1. Spatial distribution of neighborhood education and income, according to administrative division in counties (RECORD Cohort; $N=7290$ ). Table S2. Spatial distribution of rail traffic noise, according to the administrative division in counties, neighborhood urban typology and neighborhood education (RECORD Cohort Study). Table S3. Associations estimated from multilevel logistic regression between rail traffic noise estimated at the place of residence $(3 \mathrm{~A})$ and at the median noise value of $500 \mathrm{~m}$ radius street network buffers around the place of residence (3B) and annoyance due to road traffic, adjusted for individual/neighborhood socio-demographic factors (RECORD Cohort Study). Table S4. Associations estimated from multilevel logistic regression between rail traffic noise estimated at the place of residence
(5A) and at the 25th (5B), 50th (5C), and 75th percentiles (5D) of noise values of $500 \mathrm{~m}$ radius street network buffers around the place of residence and annoyance due to road traffic, adjusted for individual/ neighborhood socio-demographic factors (RECORD Cohort Study). Table S5. Modification of the association between road traffic noise at the place of residence and annoyance due to road traffic, by rail traffic noise at the place of residence, on the multiplicative and additive scales (RECORD Cohort Study; $N=3945$ ). Table S6. Modification of the association between road traffic noise and annoyance due to road traffic, by neighborhood income and education, on the additive scale (RECORD Cohort Study).

\section{Competing interests}

The authors declare that they have no competing interests.

\section{Authors' contributions}

JM designed the specific study, conducted most of the analyses, and oversaw the drafting of the manuscript with BC (study coordinator). All authors have participated in the analysis and interpretation of the data, and in the review of the manuscript drafts. AH elaborated the neighborhood typology. NK participated in the analysis and interpretation of the data. FT also participated in the conception of the data collection protocol. All authors read and approved the final manuscript.

\section{Acknowledgements}

We are grateful to INPES (and Pierre Arwidson) for its continued support since the beginning of the study. We are also grateful to Insee, the French National Institute of Statistics and Economic Studies, which provided support for the geocoding of the RECORD participants and allowed us to access to relevant geographical data (with special thanks to Pascale Breuil). We thank Geoconcept for allowing us to access to the Universal Geocoder software. We also thank the Caisse Nationale d'Assurance Maladie des Travailleurs Salariés (France) and the Caisse Primaire d'Assurance Maladie de Paris (France) for helping make this study possible. Bruitparif is also warmly thanked for providing access to the noise data and for the invaluable assistance and advices received (Marie-Alice d'Orléans, Fanny Mietlicki).

\section{Sources of funding}

Julie Méline was supported during the present work by the Regional council of lle-de-France (Program "Domaine d'Intérêt Majeur" "Health, Environment and Toxicology"). The RECORD project received support from the Institute for Public Health Research (IReSP, Institut de Recherche en Santé Publique); the National Institute for Prevention and Health Education (INPES, Institut National de Prévention et d'Education pour la Santé) (Prevention Program 2007; 2010-2011 financial support; and 2011-2013 financial support); the National Institute of Public Health Surveillance (InVS, Institut de Veille Sanitaire) (Territory and Health Program); the French Ministries of Research and Health (Epidemiologic Cohorts Grant 2008); the National Health Insurance Office for Salaried Workers (CNAM-TS, Caisse Nationale d'Assurance Maladie des Travailleurs Salariés); the lle-de-France Regional Council (Conseil Régional d'Île-de-France, DIM SEnT and CODDIM); the National Research Agency (ANR, Agence Nationale de la Recherche) (Health-Environment Program 2005); the lle-de-France Regional Health Agency (ARS, Agence Régionale de Santé) (in 2009; 2010; and 2011); the City of Paris (Ville de Paris); and the lle-de-France Youth, Sports, and Social Cohesion Regional Direction (DRJSCS, Direction Régionale de la Jeunesse, des Sports et de la Cohésion Sociale). Andraea van Hulst received support from a CIHR/Heart and Stroke Foundation of Canada Training Grant in Population Intervention for Chronic Disease Prevention, and a doctoral scholarship from the Fonds de la recherche en santé du Québec.

\section{Author details}

${ }^{1}$ Inserm, U707, Paris, France. ${ }^{2}$ Université Pierre et Marie Curie-Paris6, UMR-S 707, Faculté de Médecine Saint-Antoine, Paris, France. ${ }^{3}$ Department of Social and Preventive Medicine, Faculty of Medicine, University of Montreal, Montreal, Canada. ${ }^{4}$ Research Center of Sainte-Justine, University Hospital, Montreal, Canada. ${ }^{5}$ Centre d'Investigations Préventives et Cliniques, Paris, France. 
Received: 30 May 2013 Accepted: 28 September 2013

Published: 2 October 2013

\section{References}

1. Grange D, Chatignoux E, Gremy I: Les perceptions du bruit en lle-de-France. Rapport de l'Observatoire Régional de la Santé (ORS) Ile-de-France. In Book Les perceptions du bruit en Ile-de-France. Edited by Rapport de l'Observatoire Régional de la Santé (ORS), Ile-de-France. City: Observatoire Régionale de la Santé (ORS); 2009.

2. European Commission: Directive 2002/49/EC of the European Parliament and of the Council of 25 June 2002 relating to the assessment and management of environmental noise. In Book Directive 2002/49/EC of the European Parliament and of the Council of 25 June 2002 relating to the assessment and management of environmental noise. City: Official Journal of the European Communities; 2002:12-25. 12-25.

3. Miedema $H$, Janssen $\mathrm{S}$, Rokho $\mathrm{K}$ : Burden of disease from environmental noise - Quantification of healthy life years lost in Europe. In Book Burden of disease from environmental noise - Quantification of healthy life years lost in Europe. City: World Health Organization; 2011:91-98. 91-98.

4. Babisch W, Neuhauser $H$, Thamm M, Seiwert M: Blood pressure of 8-14 year old children in relation to traffic noise at home-results of the German Environmental Survey for Children (GerES IV). Sci Total Environ 2009, 407:5839-5843.

5. Jones K: Environmental noise and health: a review. In Book Environmental noise and health: a review. City: UK Civil Aviation Authority; 2010:56. 56.

6. Berglund B, Lindvall T, Schwela D: Guidelines for Community Noise. In Book Guidelines for Community Noise. City: The World Health Organization; 1999.

7. Fidell S, Barber D, Schultz T: Updating a dosage-effect relationship for the prevalence of annoyance due to general transportation noise. J Acoust Soc Am 1991, 89:221-233.

8. Finegold L, Harris S, von de Gierke H: Community annoyance and sleep disturbance: updated criteria for assessing the impacts of general transportation noise on people. Noise Control Eng J 1994, 42:25-30.

9. Maynard R, Berry B, Flindell I: Environmental Noise and Health in the UK A report published by the Health Protection Agency on behalf of the ad hoc Expert Group on the Effects of Environmental Noise on Health. In Book Environmental Noise and Health in the UK - A report published by the Health Protection Agency on behalf of the ad hoc Expert Group on the Effects of Environmental Noise on Health. City: Health Protection Agency; 2010:110. 110

10. Miedema HM, Oudshoorn CG: Annoyance from transportation noise: relationships with exposure metrics DNL and DENL and their confidence intervals. Environ Health Perspect 2001, 109:409-416.

11. Miedema HM, Vos H: Exposure-response relationships for transportation noise. J Acoust Soc Am 1998, 104:3432-3445.

12. Schultz TJ: Synthesis of social surveys on noise annoyance. J Acoust SoC Am 1978, 64:377-405.

13. Van Kempen E, Staatsen B, Van Kamp I: Selection and evaluation of exposure-effect-relationships for health impact assessment in the field of noise and health - RIVM report 630400001/2005. In Book Selection and evaluation of exposure-effect-relationships for health impact assessment in the field of noise and health - RIVM report 630400001/2005. City: RIVM; 2005.

14. Bruitparif: Etude SURVOL (Surveillance sanitaiRe et enVironnementale des plates-formes aéroportuaires de rOissy, orLy, le bourget) - Volet bruit, Rapport d'étape. In Book Etude SURVOL (Surveillance sanitaiRe et enVironnementale des plates-formes aéroportuaires de rOissy, orly, le bourget) - Volet bruit, Rapport d'étape. City: Bruitparif; 2011.

15. Aasvang G, Engdahl B, Rothschild K: Annoyance and self-reported sleep disturbances due to structurally radiated noise from railway tunnels. Appl Acoust 2007, 68:970-981.

16. Gidlof-Gunnarsson A, Ogren M, Jerson T, Ohrstrom E: Railway noise annoyance and the importance of number of trains, ground vibration, and building situational factors. Noise Health 2012, 14:190-201.

17. Whitfield A: Assessment of noise annoyance in three distinct communities living in close proximity to a UK regional airport. Int $J$ Environ Health Res 2003, 13:361-372.

18. Fyhri $A$, Klaeboe R: Direct, indirect influences of income on road traffic noise annoyance. J Environ Psychol 2006, 26:27-37.

19. Chaix B, Bean K, Leal C, Thomas F, Havard S, Evans D, Jego B, Pannier B: Individual/neighborhood social factors and blood pressure in the
RECORD Cohort Study: which risk factors explain the associations? Hypertension 2010, 55:769-775.

20. Guski R, Felscher-Suhr U: The concept of noise annoyance: how international experts see it. J Sound Vib 1999, 223:513-527.

21. Van Hulst A, Thomas F, Barnett TA, Kestens Y, Gauvin L, Pannier B, Chaix B: A typology of neighborhoods and blood pressure in the RECORD Cohort Study. J Hypertens 2012, 30:1336-1346.

22. Eriksson C, Nilsson ME, Stenkvist D, Bellander T, Pershagen G: Residential traffic noise exposure assessment: application and evaluation of European Environmental Noise Directive maps. J Expo Sci Environ Epidemiol 2013, 23:531-538.

23. Havard S, Reich BJ, Bean K, Chaix B: Social inequalities in residentia exposure to road traffic noise: an environmental justice analysis based on the RECORD Cohort Study. Occup Environ Med 2011, 68:366-374.

24. Berke EM, Koepsell TD, Moudon AV, Hoskins RE, Larson EB: Association of the built environment with physical activity and obesity in older persons. Am J Public Health 2007, 97:486-492.

25. Chaix B, Jouven X, Thomas F, Leal C, Billaudeau N, Bean K, Kestens Y, Jego $B$, Pannier B, Danchin N: Why socially deprived populations have a faster resting heart rate: impact of behaviour, life course anthropometry, and biology-the RECORD Cohort Study. Soc Sci Med 2011, 73:1543-1550.

26. Leal C, Bean K, Thomas F, Chaix B: Are associations between neighborhood socioeconomic characteristics and body mass index or waist circumference based on model extrapolations? Epidemiology 2011, 22:694-703

27. Kaufman JS: Interaction reaction. Epidemiology 2009, 20:159-160.

28. Bocquier A, Cortaredona S, Boutin C, David A, Bigot A, Chaix B, Gaudart J, Verger $P$ : Small-area analysis of social inequalities in residential exposure to road traffic noise in Marseilles, France. Eur J Public Health 2013, 23:540-546

29. Abo-Qudais S, Abu-Qdais H: Perceptions and attitudes of individuals exposed to traffic noise in working places. Building Environ 2005 40:778-787.

30. Alimohammadi I, Nassiri P, Azkhosh M, Hoseini M: Factors affecting road traffic noise annoyance among white collar employees working in Teheran. Iran J Environ Health Sci Eng 2010, 7:25-34.

31. Koushki P, Cohn L, Felimban A: Urban traffic noise in Riyadh, Saudi Arrabia: perceptions and attitudes. J Transp Eng 1993, 119:751-762.

32. Ohrstrom E, Barregard L, Andersson E, Skanberg A, Svensson H, Angerheim P: Annoyance due to single and combined sound exposure from railway and road traffic. J Acoust Soc Am 2007, 122:2642-2652.

33. Karlson K, Holm A, Breen R: Comparing regression coefficients between same-sample nested models using logit and probit: a new method. Sociol Methodol 2012, 42:286-313.

34. Bruitparif: Impact sanitaire du bruit dans l'agglomération parisienne: quantification des années de vie en bonne santé perdues - Note de synthèse sur l'application à l'agglomération parisienne de la méthode de I'Organisation Mondiale de la Santé (OMS) pour la détermination de la morbidité liée au bruit. In Book Impact sanitaire du bruit dans l'agglomération parisienne: quantification des années de vie en bonne santé perdues - Note de synthèse sur l'application à l'agglomération parisienne de la méthode de l'Organisation Mondiale de la Santé (OMS) pour la détermination de la morbidité liée au bruit. City: Bruitparif; 2011:23. 23.

35. Chaix B, Billaudeau N, Thomas F, Havard S, Evans D, Kestens Y, Bean K: Neighborhood effects on health: correcting bias from neighborhood effects on participation. Epidemiology 2011, 22:18-26.

36. McCrae IS, Williams ID: Road traffic pollution and public nuisance. Sci Total Environ 1994, 146/147:81-91.

37. Kohlhuber M, Mielck A, Weiland SK, Bolte G: Social inequality in perceived environmental exposures in relation to housing conditions in Germany. Environ Res 2006, 101:246-255.

doi:10.1186/1476-072X-12-44

Cite this article as: Méline et al.: Transportation noise and annoyance related to road traffic in the French RECORD study. International Journal of Health Geographics 2013 12:44. 